\title{
Nitrate and ammonium depletion rates and preferences during a Baltic spring bloom
}

\author{
Timo Tamminen \\ Tvärminne Zoological Station, FIN-10900 Hanko, Finland
}

\begin{abstract}
Nitrate and ammonium depletion potential of the planktonic community was studied during a spring bloom off the SW coast of Finland in the Baltic Sea. Depletion rates were measured after nutrient enrichments with different concentrations and combinations of $\mathrm{NO}_{3}, \mathrm{NH}_{4}$ and $\mathrm{PO}_{4}$. Depletion kinetics, $N$ source preferences, mutual inhibition, utilization efficiency and $\mathrm{P}$ stimulation of $\mathrm{N}$ depletion were estimated. During the bloom peak, the community showed a depletion potential over $24 \mathrm{~h}$ equivalent to the total wintertime accumulation of inorganic nitrogen. A clear succession in $\mathrm{N}$ source preferences, mutual inhibition and utilization efficiency illustrated the shift from $\mathrm{NO}_{3}$ to $\mathrm{NH}_{4}$ as the basis for nitrogenous nutrition of the community. The succession of these potential qualities was gradual, in sharp contrast to the abrupt depletion of $\mathrm{NO}_{3}$ from the water column and to profound changes in the species composition of the phytoplankton community. This gradual succession allowed the community to effectively utilize both $\mathrm{NO}_{3}$ and $\mathrm{NH}_{4}$ as $\mathrm{N}$ sources according to their availability. The relative proportions of new and regenerated production seem therefore to be regulated mainly by relative supply rates of $\mathrm{NO}_{3}$ through physical transport and $\mathrm{NH}_{4}$ through mineralization processes within the community, while inherent preferences of the community play a subordinate role.
\end{abstract}

KEY WORDS: Phytoplankton - Nitrogen sources - Depletion rate - Preference Inhibition - Spring bloom Baltic Sea

\section{INTRODUCTION}

The spring bloom in temperate dimictic waters is based on the physical conditions of the surface layer (Sverdrup 1952) and the wintertime accumulation of inorganic nutrients in the whole water body. Nitrate is the dominant form of inorganic nitrogen at the commencement of the spring bloom. Nitrogen is generally considered to be the limiting nutrient for marine and coastal planktonic communities (Ryther \& Dunstan 1971), and nitrate depletion during the bloom is obviously a major cause of the rapid postbloom decline of planktonic biomass.

Dugdale \& Goering (1967) introduced the concepts of new and regenerated production, distinguished on the grounds of utilized nitrogen sources. Oxidized forms of $N$ (nitrate, gaseous nitrogen) represent the basis for new production, and reduced $\mathrm{N}$ (ammonium, organic $\mathrm{N}$ compounds) the basis for regenerated production. These chemical categories reflect temporal and spatial differences in the nutrient supply of the community.

Reduced nutrients represent immediate, autochthonous supply via regeneration within the planktonic community, and oxidized nutrients represent allochthonous supply, based on accumulation and/or transport over larger temporal and spatial scales (Dugdale \& Goering 1967, reviews by Eppley 1981 and Goldman 1984). The spring bloom thus represents a typical, dynamic outburst of predominantly new production.

The preference order $\mathrm{NH}_{4}>$ urea $>\mathrm{NO}_{3}$ for nitrogenous nutrients has been generally reported from several offshore (Eppley et al. 1971, 1973, 1977, Kanda et al. 1985), coastal (McCarthy 1972, Harvey \& Caperon 1976. McCarthy et al. 1977, Paasche \& Kristiansen 1982a, Kristiansen 1983, Furnas et al. 1986, Sahlsten et al. 1988, Sörensson et al. 1989) and freshwater (McCarthy et al. 1982, Mitamura \& Saijo 1986) environments, with the exception of the spring bloom 
period, when nitrate usually dominates nitrogen uptake (e.g. Sahlsten et al. 1988).

Most of these preference evaluations have been based either on direct comparisons of uptake rates of different nitrogen sources, measured with ${ }^{15} \mathrm{~N}$ techniques, or on the relative preference index (RPI) proposed by McCarthy et al. (1977). This index compares the fractions of a given form of $\mathrm{N}$ in uptake and in concentration.

This approach has revealed some surprisingly universal features of nitrogenous nutrition of both marine and freshwater phytoplankton (McCarthy et al. 1982). The analysis of in situ uptake measurements and concentrations is, however, hampered by (1) analytical difficulties, due to the often extremely low nutrient concentrations in surface layers (e.g. Eppley et al. 1977); (2) the fact that ${ }^{15} \mathrm{~N}$ uptake measurements often require substrate additions which significantly affect ambient nutrient concentrations (e.g. McCarthy 1972 , Eppley et al. 1973, 1977), thus producing results which represent something between natural uptake rates and the uptake potential of the community, if a kinetic assay on several nutrient addition levels is not performed; (3) the use of pool sizes of nutrients in the RPI equation.

The last mentioned property of the RPI is clearly problematic, because availability of a given nutrient during regenerated production is more a function of supply of the nutrient through mineralization than of concentration as such. Measured nutrient stocks during summer periods would often be depleted within hours if effective mineralization did not occur (e.g. Paasche \& Kristiansen 1982b, Furnas et al. 1986 , Andersen et al. 1991). The RPI exaggerates preference of the nitrogen sources which are rapidly supplied by mineralization, that is, regenerated $\mathrm{N}$ in the sense of Dugdale \& Goering (1967)

If different nitrogen sources are not equally available and therefore cannot be freely selected from, true preference is difficult to establish. It could therefore be argued that preference in a strict sense can be evaluated only experimentally, by manipulating nutrient availability. Experimental studies on nitrogen source preferences have been conducted mainly with algal cultures, and the preference of $\mathrm{NH}_{4}$ over $\mathrm{NO}_{3}$ and urea has usually been confirmed (e.g. Conway 1977, Molloy \& Syrett 1988a, b), as might be expected on energetical grounds. Experiments with natural phytoplankton are not as numerous, and usually unnaturally high nutrient additions have been utilized. McCarthy \& Eppley (1972) showed that $\mathrm{NH}_{4}$ additions suppressed both $\mathrm{NO}_{3}$ and urea uptake of marine phytoplankton and that urea and $\mathrm{NO}_{3}$ suppressed each other However, the experimental units were heavily enriched with nutrients. Successional experi- mental data on nitrogen source preferences are, to my knowledge, nonexistent.

In this study, a very simple approach was used for the study of nitrogenous nutrition of the planktonic community during a spring bloom in the Baltic Sea. Depletion rates (change in concentration per unit time) were measured after nutrient enrichments. Nitrate and ammonium were added in experimental units in several concentrations to estimate depletion kinetics. Also, equimolar additions of nitrate and ammonium were used to evaluate uptake preferences of these nitrogen sources, and phosphate additions were used to study the dependence of nitrogen depletion on phosphorus availability.

Net change in nutrient concentration is of course the combined result of nutrient uptake and mineralization. The depletion rate after nutrient enrichment thus represents excess of uptake over mineralization. However, during the spring bloom, which is initiated at near-zero temperatures in the Baltic, depletion rate is assumed to closely reflect nutrient uptake. This is supported by the observed succession of potential remineralizers (mesozooplankton, protozoa, heterotrophic nanoflagellates and bacterioplankton), as well as by a study which calculated that ca $80 \%$ of primary production was based on $\mathrm{NO}_{3}-\mathrm{N}$ utilization during the study period (Lignell et al. 1993). Towards early summer, depletion rates doubtless become increasingly affected by mineralization processes, therefore producing underestimates of uptake.

\section{MATERIAL AND METHODS}

Sampling. The study was conducted off the SW coast of Finland in the Baltic Sea, from 22 April until 16 June 1988. The sampling station was located outside the outer archipelago zone, some $6 \mathrm{~km}$ off the Tvärminne Zoological Station (on the Hanko peninsula) at the entrance to the Gulf of Finland. The study was part of an ecological spring bloom dynamics study by the project PELAG, which covered hydrological, chemical and biological characteristics of the whole water column (depth $42 \mathrm{~m}$ ). Part of these data are presented here as the background for experimental results of this study, by kind permission of various participants in the project (for a more detailed presentation of the carbon cycle see Lignell et al. 1993). Samples for nitrogen depletion experiments were taken from the surface layer $(0.5 \mathrm{~m})$.

Experiments. Each sample was divided into 2 I subsamples in $2.5 \mathrm{l}$ glass bottles which were enriched with nutrients as shown in Table 1 . The largest nutrient additions were selected to correspond to the initial bloom conditions in terms of inorganic $N$ and $P$. Incu- 
Table 1 Experimental design for depletion rate measure-

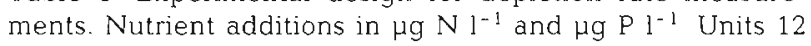
and 13 were included when phosphate depletion began in the water column (5 May)

\begin{tabular}{|crcc|}
\hline Unit & $\mathrm{NO}_{3}-\mathrm{N}$ & $\mathrm{NH}_{4}-\mathrm{N}$ & $\mathrm{PO}_{4}-\mathrm{P}$ \\
\hline 1 & 0 & 0 & 0 \\
2 & 5 & 0 & 0 \\
3 & 20 & 0 & 0 \\
4 & 50 & 0 & 0 \\
5 & 100 & 0 & 0 \\
6 & 0 & 5 & 0 \\
7 & 0 & 20 & 0 \\
8 & 0 & 50 & 0 \\
9 & 0 & 100 & 0 \\
10 & 20 & 20 & 0 \\
11 & 50 & 50 & 0 \\
12 & 50 & 0 & 20 \\
13 & 0 & 50 & 20 \\
\hline
\end{tabular}

bations started before noon, approximately $1 \mathrm{~h}$ after sampling. Nutrient additions were fresh dilutions of stock solutions of $\mathrm{NH}_{4} \mathrm{Cl}_{1} \mathrm{KNO}_{3}$ and $\mathrm{KH}_{2} \mathrm{PO}_{4}$. All glassware and plastic laboratory gear were acid-washed.

Incubations took place outdoors, sheltered from direct sunlight, in order to follow the natural irradiation cycle. Irradiation level was ca $13 \%$ of surface irradiance, corresponding to light levels at 3 to $4 \mathrm{~m}$ depth at the sampling location. Sampling times for nitrate and ammonium analyses were 7 and $24 \mathrm{~h}$ after nutrient additions.

Analyses. Ammonium was analyzed manually using the indophenol blue method after Koroleff (1976), in duplicate with individual blanks for each unit (spectrophotometer light path $70 \mathrm{~mm}$ ). A $>0.5 \mu \mathrm{g} \mathrm{NH} \mathrm{N}_{4}-\mathrm{N} \mathrm{l}^{-1}$ difference between replicates is exceptional with the procedure used in our laboratory. Phosphate was analyzed according to the molybdate method (Koroleff 1976). Nitrate analysis was based on the reduction of nitrate to nitrite in a copperized cadmium reductor and subsequent azo dye formation, and was performed with Flow Injection Analysis slightly modified after Johnson \& Petty (1983). A Tecator 5020 FIAstar apparatus was used for the analysis. Duplicate measurements from duplicate or triplicate samples were performed to compensate for the shorter light path $(10 \mathrm{~mm})$ available in spectrophotometric detection. Chlorophyll a was measured fluorometrically with ethanol extraction, and primary productivity with ${ }^{14} \mathrm{C}$ in situ incubations (for details see Lignell et al. 1993).

Depletion rates. Depletion rates were calculated as the difference between time-zero and sampling values, divided by incubation time. Because of the drastic differences in depletion rates over the course of the stucy period, only the shortest sampling times and largest nutrient additions could be used in calculations during the bloom peak, while the shortest incubation times did not always produce reliable differences in concentration during pre- and postbloom stages.

Kinetic parameters for nutrient depletion were calculated with the so-called Lineweaver-Burk transformation of Michaelis-Menten kinetics, as presented by Wright \& Hobbie (1966), from Units 1 to $5\left(\mathrm{NO}_{3}\right)$ and Units 1 and 6 to $9\left(\mathrm{NH}_{4}\right.$; Table 1$)$.

Nitrate and ammonium preferences were calculated by dividing the depletion rates for $\mathrm{NO}_{3}$ and $\mathrm{NH}_{4}$ in the equimolar addition units by respective total $\mathrm{N}\left(\mathrm{NO}_{3}+\right.$ $\mathrm{NH}_{4}$ ) depletion rates in those units (Units 10 and 11; Table 1).

Inhibition by the alternative $\mathrm{N}$ source was calculated by dividing depletion rates for each nutrient in the combined addition unit (Unit 11; Table 1) by corresponding rates in the single addition units (Units 4 and 8; Table 1). Inhibition was expressed as \% decrease from single addition units.

U:ilization efficiency of single nitrogen sources was calculated by dividing the depletion rates for $\mathrm{NO}_{3}$ and $\mathrm{NH}_{4}$ in the single $\left(100 \mu \mathrm{g} \mathrm{N} \mathrm{^{-1 }}\right)$ addition units by total $\mathrm{N}$ depletion rate in the combined $\left(50+50 \mu \mathrm{g} \mathrm{N} \mathrm{l}^{-1}\right)$ addition unit (Units 5 and 9 , and Unit 11; Table 1). Values over $100 \%$ indicate dependence on a single nitrogen source, $100 \%$ represents equal efficiency regardless of the $\mathrm{N}$ source, and values below $100 \%$ indicate inability to fulfill $\mathrm{N}$ requirements with the $\mathrm{N}$ source in question.

Phosphate stimulation of $\mathrm{N}$ depletion rates was calculated by dividing the depletion values from phosphate addition units (Units 12 and 13; Table 1) by values from corresponding units without phosphate addition (Units 4 and 8; Table 1). Stimulation was expressed as \% increase relative to single addition units.

\section{RESULTS}

\section{Nitrate and ammonium distribution}

Winter nitrate concentrations were approximately $100 \mu \mathrm{g} \mathrm{NO}_{3}-\mathrm{N}^{-1}$ in the whole water column, except for a thin layer of nutrient-rich water of low salinity $(<3 \%$ ) below the ice (Fig. 1). This influence of outflow from the inner archipelago could not be detected at the sampling station after the break-up of the ice cover, by mid-April, when a salinity of $6.1 \%$ prevailed in the whole water column

The spring was characterized by rapid and thorough depletion of nitrate in the whole water column during 


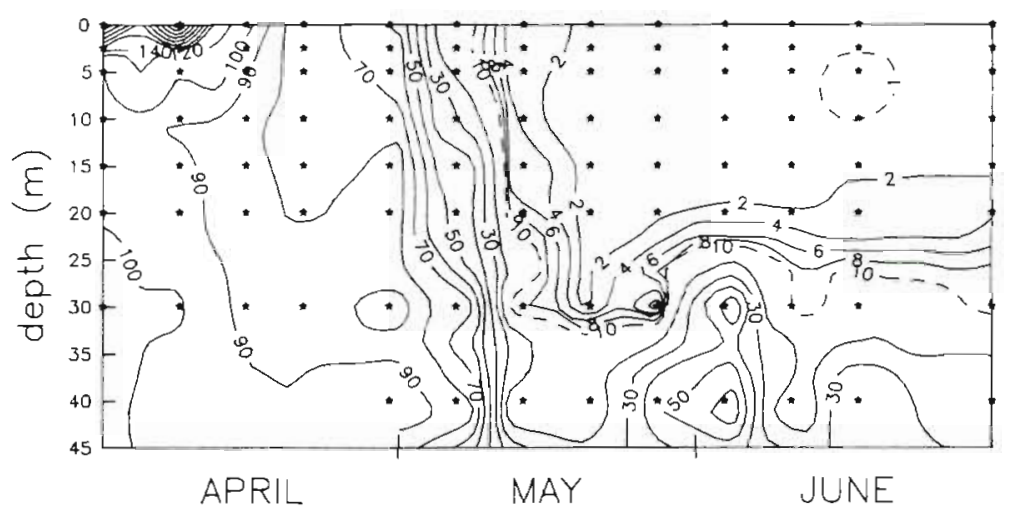

Fig. 1. Nitrate distribution in the water column ( $\left.\mu \mathrm{g} \mathrm{NO}_{3}-\mathrm{N}^{-1}\right)$, Baltic Sea

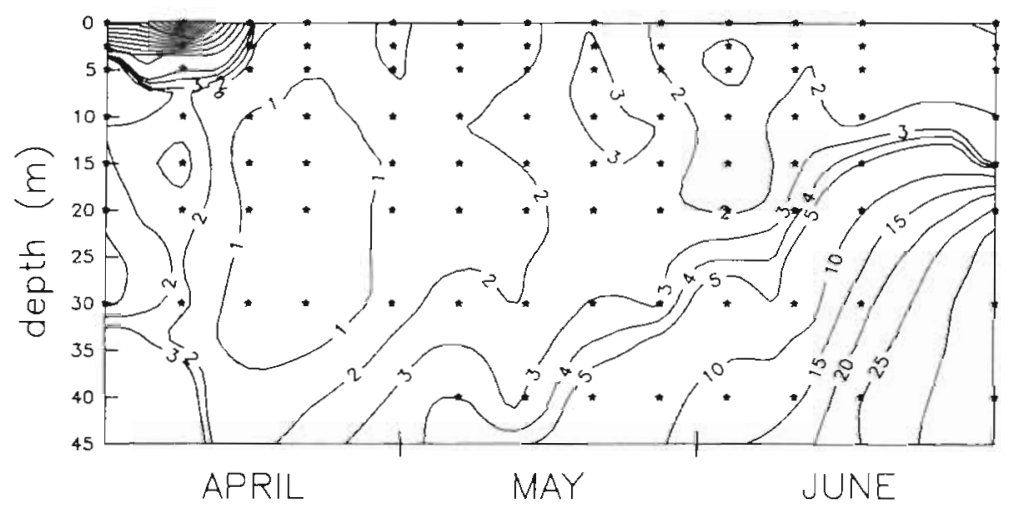

Fig. 2. Ammonium distribution in the water column ( $\mu \mathrm{NH}_{4}-\mathrm{N} \mathrm{l}^{-1}$ ), Baltic Sea

the first 2 wk of May, although the depletion in the surface layer had already started on 22 April, and the uppermost $10 \mathrm{~m}$ was depleted after the first week of May (Fig. 1). In the latter half of May, thermal stratification started to develop in the upper water column, leading to a thermocline around 10 to $15 \mathrm{~m}$ at the end of May (data not shown). This development coincided with an upwelling of more saline (7.0\%), nutrient-rich water. The upwelling resulted in a nutricline around 25 $m$ which persisted until early July (Fig. 1).

With the exception of high values immediately under the ice, ammonium concentrations were low in the whole water column until the late May upwelling (Fig. 2), when the vertical distribution of ammonium reflected the development of the nutricline observed in both nitrate (Fig, 1) and phosphate concentrations (data not shown).

\section{Phytoplankton succession and nitrogen depletion kinetics}

The study period covered the spring bloom from its initiation, when winter nitrate levels prevailed, to the early summer period, with low levels of nutrients and phytoplankton biomass and production (Fig. 3). Succession of the phytoplankton community (Heiskanen 1993) was dominated by dinoflagellates (60 to $80 \%$ of phytoplankton biomass) until late May. Peridiniella (= Gonyaulax) catenata was abundant throughout the bloom and dominant during the rising phase, while Glenodinium sp. showed a peak in mid-May. In the rising phase of the bloom, cold water diatoms (Achnanthes taeniata, Chaetoceros holsaticus, C. wighamii) were also important (ca $30 \%$ of total biomass), and they were replaced by Skeletonema costatum during the declining phase. In early June, $S$. costatum was the dominant species, replaced by Eutreptiella spp. and small flagellates in mid-June.

During April, high nitrate concentrations still prevailed in the surface layer (Fig. 1). Consequently, nitrate additions did not affect nitrate depletion rates, indicating that nitrate was being depleted at the saturation level of the community (Fig. 4A). At the time of the first experiment, ammonium additions were not depleted at all, and maximum depletion rate was low at the end of April (Fig. 4B). During the bloom peak (May dates), both nitrate and ammonium were depleted very effectively, and depletion rates could be approximated with Michaelis-Menten kinetics (Fig. 4A, B).

In the early summer stage, depletion rates decreased drastically (note the difference in scales between Fig $4 \mathrm{~A}, \mathrm{~B}$ and $4 \mathrm{C}, \mathrm{D}$ ), and depletion did not follow Michaelis-Menten kinetics, except for ammonium on 2 June (Fig. 4C, D). Otherwise, the largest additions led

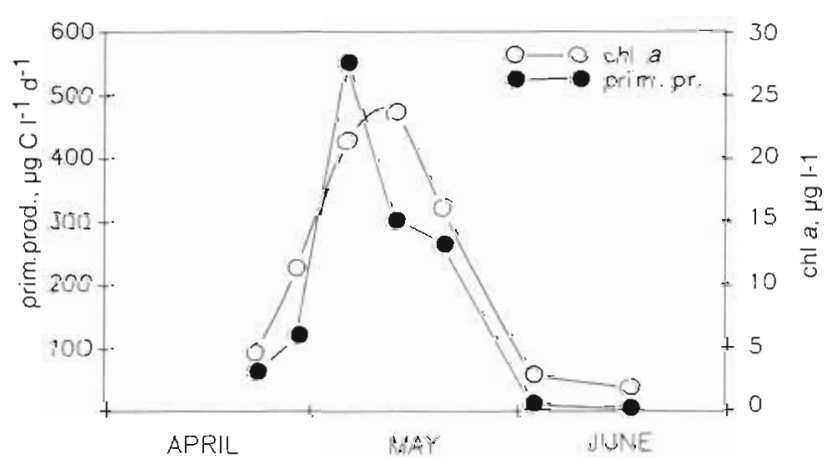

Fig. 3. Chlorophyll a and primary productivity in the surface layer $(0.2 \mathrm{~m})$ 

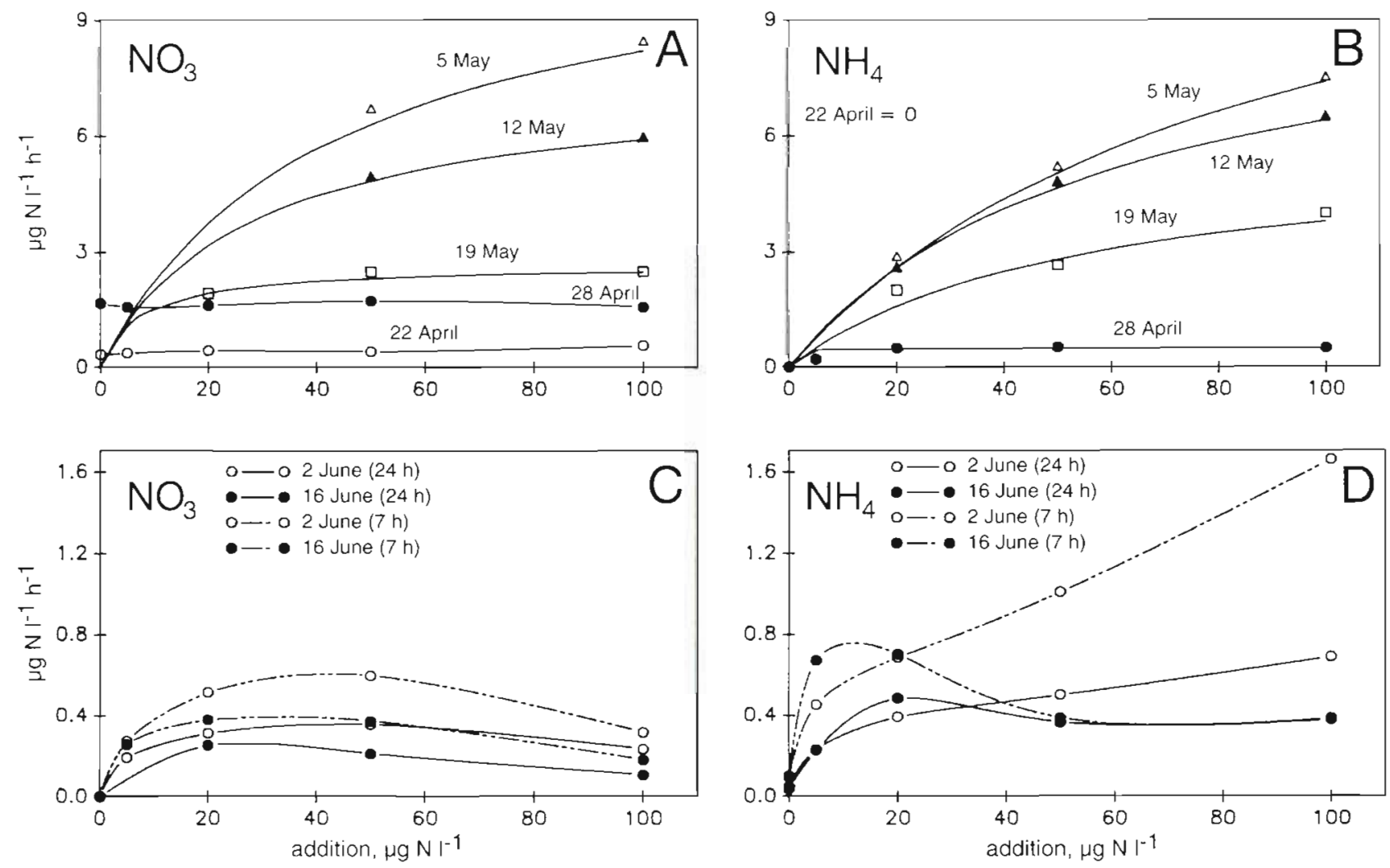

Fig. 4. Nitrate and ammonium depletion kinetics during the experimental period. (A) Nitrate, April and May; (B) ammonium, April and May; (C) nitrate, June; (D) ammonium, June. Symbols represent averages of replicates. The saturation curves (May) are based on kinetic parameters derived from linear transformation (turnover time, $T$, vs substrate addition, A) of Michaelis-Menten

kinetics. April dates: $24 \mathrm{~h}$ incubations, May dates: $7 \mathrm{~h}$ incubations. Note the different scales in upper and lower graphs

to decreased depletion rates. This was especially pronounced with ammonium in mid-June, when depletion was clearly more effective with moderate ammonium additions (Fig. 4D).

The maximum depletion rates ( $V_{\max }$ ) for both nitrate and ammonium were very high during the bloom peak (Fig. 5). Although the depletion rates measured with the largest additions $\left(100 \mu \mathrm{g} \mathrm{N}^{-1}\right)$ were slightly higher for $\mathrm{NO}_{3}$ than for $\mathrm{NH}_{4}$ (Fig. 4), different uptake kinetics already produced a higher maximum depletion rate for ammonium on 5 May (Fig. 5). During the bloom succession, maximum depletion rates for ammonium clearly exceeded those for nitrate (Fig. 5; values for June are the highest rates recorded in the June experiments, due to the poor fit of Michaelis-Menten kinetics; see Fig. 4).

In the $100 \mu \mathrm{g} \mathrm{N}^{-1}$ additions there were differences in the time course of depletion rates at different stages of the bloom. During the highest peak in primary productivity (Fig. 3), nitrogen depletion rates were far higher during the $7 \mathrm{~h}$ compared to the $24 \mathrm{~h}$ incubations (Fig. 6). During the subsequent chlorophyll maximum (Fig. 3), shorter incubations already produced decreas- ing depletion rates, but $24 \mathrm{~h}$ depletion increased (Fig. 6). After this date, nitrate depletion was approximately linear over time, in contrast to ammonium, which showed consistently higher depletion rates in shorter incubations (Fig, 6).

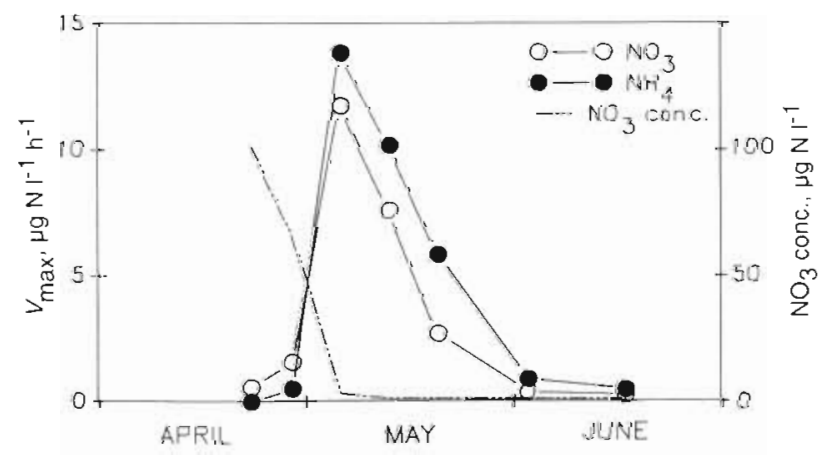

Fig. 5. Maximum depletion rate $\left(V_{\max }\right)$ of nitrate and ammonium, and surface nitrate concentration during the experimental period. May dates: $7 \mathrm{~h}$ incubations; others: $24 \mathrm{~h}$ incubations. For May dates, values are calculated kinetic rates, for others, the highest rates obtained in those experiments 


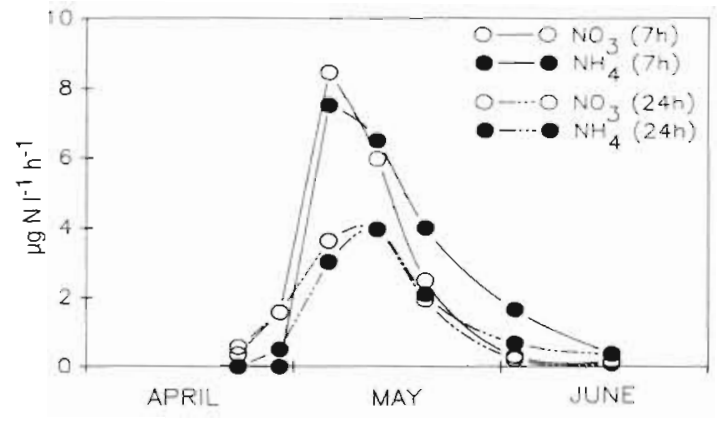

Fig. 6. Depletion rates of nitrate and ammonium in $7 \mathrm{~h}$ and $24 \mathrm{~h}$ incubations, measured with $100 \mathrm{\mu g} \mathrm{N} \mathrm{l}^{-1}$ additions

\section{$\mathrm{N}$ source preferences, utilization efficiency and inhibition}

Depletion rates in the equimolar addition units (Units 10 and 11; Table 1) revealed a clear succession in nitrogen source preferences (Fig. 7). During the rising phase of the bloom, nitrate was highly preferred over ammonium, during the peak both nitrogen sources showed equal preference, and during the declining phase ammonium preference increased steadily until no nitrate was depleted if ammonium was present (Fig. 7A). The pattern was identical irrespective of added concentrations (20 or $50 \mu \mathrm{g} \mathrm{N} \mathrm{I}^{-1}$ each) or incubation times used (Fig. 7B).

During the bloom peak ( 5 to 12 May), utilization efficiency of both $\mathrm{N}$ sources was practically $100 \%$, indicating that $\mathrm{N}$ depletion was uniform regardless of the $N$ sources available (Fig. $7 \mathrm{C}$ ). In the initial phases of the bloom, nitrogen was depleted far more efficiently if it was available as nitrate only, whereas during the decreasing phase, the opposite was observed (Fig, 7C). Ammonium showed almost a mirror image except for the last date. $N$ depletion in the combined addition unit $\left(50+50 \mu \mathrm{g} \mathrm{N}^{-1}\right)$ consisted then entirely of ammonium depletion, but the larger ammonium addition $(100 \mu \mathrm{g}$ $\mathrm{N}^{-1}$ ) did not lead to more effective utilization (Figs. 4D \& 7C).

During the first experiment, nitrate was abundant in the water column and completely inhibited ammonium uptake. Thereafter only a slight and diminishing inhibition of ammonium uptake by nitrate was observed (Fig. 7D). In contrast, increasing inhibition of nitrate depletion by the presence of ammonium was observed during the decreasing phase of the bloom (Fig. 7D).

This was also observed transiently during the rising phase (28 April; Fig. 7D). At that point, nitrate was still
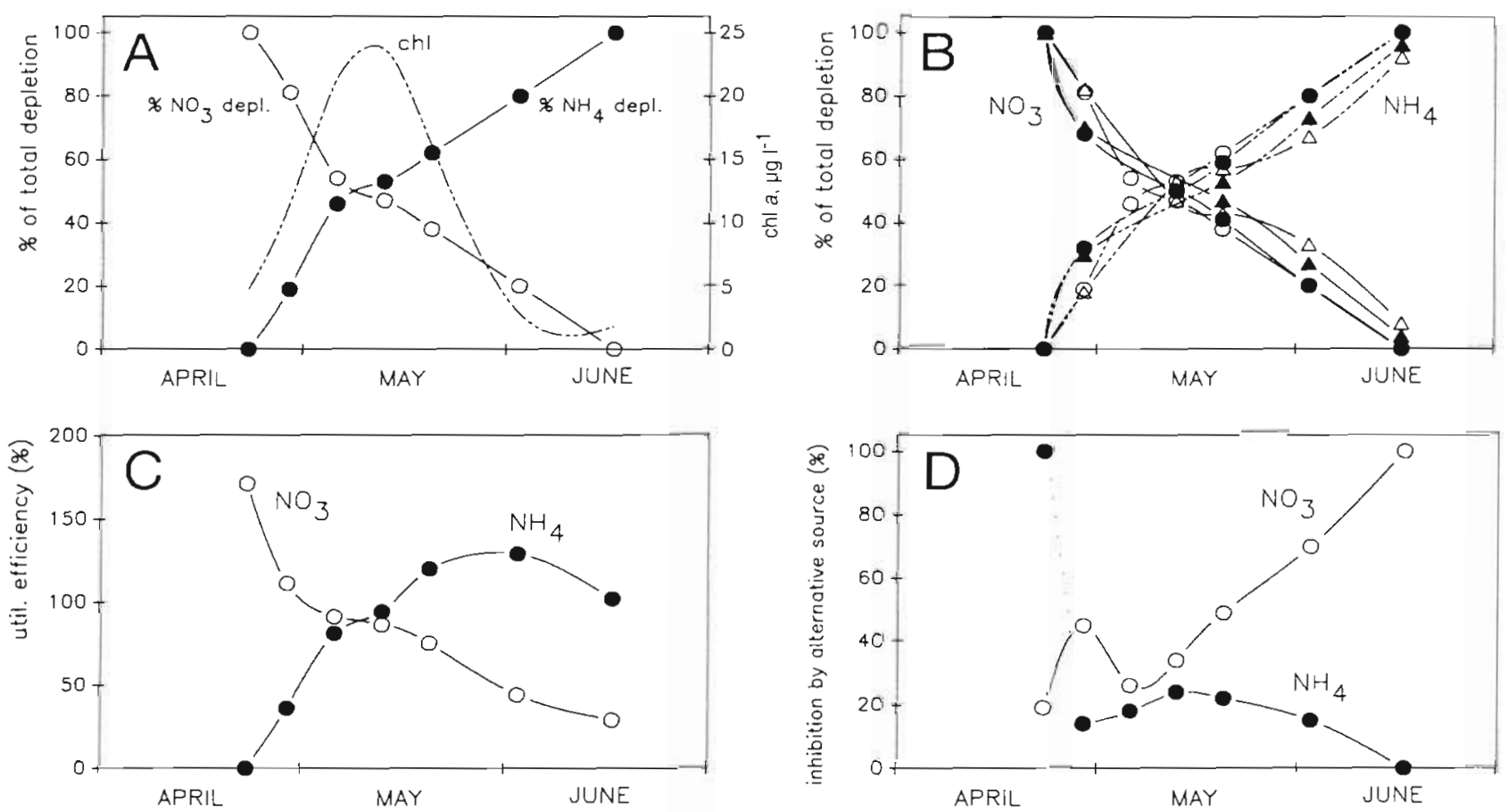

Fig. 7 Nitrate and ammonium preference, utilization efficiency and mutual inhibition. (A) Preference (\% of total depletion in

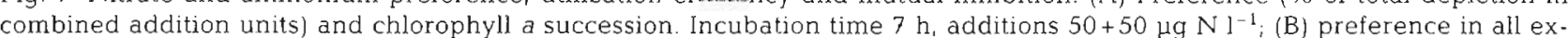
periments. Open symbols: $7 \mathrm{~h}$ incubations; filled symbols: $24 \mathrm{~h}$ incubations. Circles: $50+50 \mu \mathrm{g} \mathrm{N} \mathrm{I}^{-1}$ addition units; triangles: $20+20 \mu \mathrm{g} \mathrm{N}^{-1}$ addition units. (C) Utilization efficiency of nitrate and ammonium (depletion rate for each nutrient in single

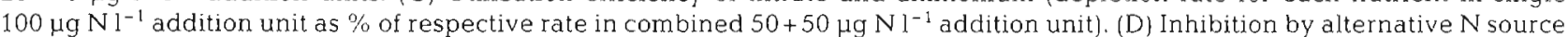




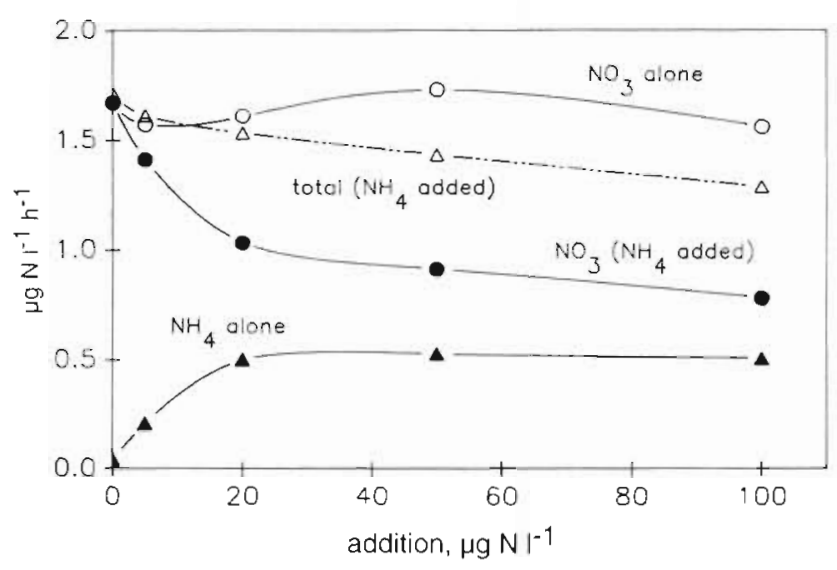

Fig. 8. Depletion rates on 28 April, 24 h incubations. Nitrate depletion as a function of nitrate additions (O), ammonium depletion as a function of ammonium additions ( $\mathbf{A})$, nitrate depletion as a function of ammonium additions ( $(\mathbf{)}$ ), and total $\mathrm{N}\left(\mathrm{NO}_{3}+\mathrm{NH}_{4}\right)$ depletion as a function of ammonium additions $(\Delta)$. Ambient nitrate concentration was $61 \mu \mathrm{g} \mathrm{NO} \mathrm{NO}_{3} \mathrm{~N} \mathrm{l}^{-1}$

abundant in the water column (Fig. 1), and nitrate depletion rates were unaffected by nitrate additions (Figs, 4 \& 8). However, ammonium significantly inhibited nitrate depletion even at $5 \mu \mathrm{g} \mathrm{NH}_{4}-\mathrm{N}^{-1}$ addition levels (Fig. 8). Although ammonium depletion increased with increasing $\mathrm{NH}_{4}$ additions, this was not sufficient to compensate for the lowered nitrate depletion, and total $\mathrm{N}$ depletion decreased steadily with increasing ammonium additions (Fig. 8).

\section{Phosphate stimulation}

Phosphate was not depleted from the water column as rapidly as nitrate (Fig. 9). During May, phosphate additions did not affect nitrate or ammonium depletion rates, but towards early summer, significant stimulation occurred for both nitrogen sources (Fig. 9). Ammonium depletion rate more than doubled due to phosphate addition on 16 June.

The inorganic N:P ratio $\left(\mathrm{DIN}=\mathrm{NO}_{3}+\mathrm{NH}_{4}\right)$ was close to the Redfield ratio ( $w: w=7$ ) before depletion from the water column started in late April. Because of faster depletion of nitrate, the ratio decreased to extremely low values throughout May, and it increased towards early summer, when phosphate stimulation of $\mathrm{N}$ depletion emerged (Fig. 9).

\section{Relations to chlorophyll $a$ and primary productivity}

The general succession of nitrogen depletion potential (Figs. 5 \& 6) was mainly related to phytoplankton succession (Fig. 3). When $\mathrm{N}$ depletion rates were nor-

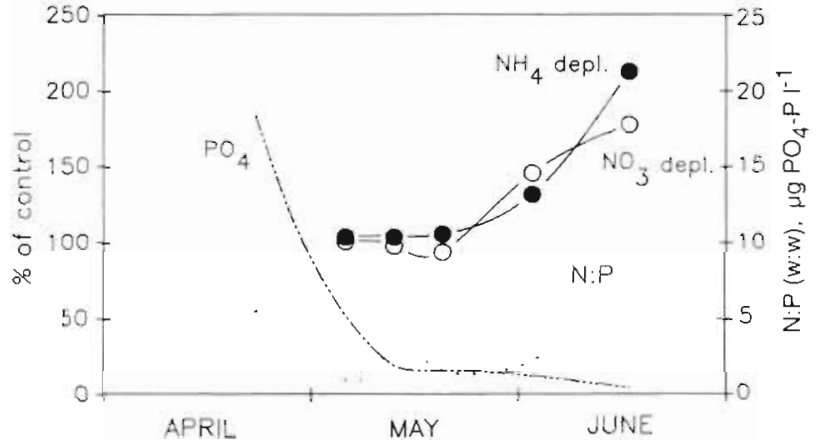

Fig. 9. Phosphate concentration ( $\mu \mathrm{g} \mathrm{PO}_{4}-\mathrm{Pl}^{-1}$ ) and $\mathrm{N}$ :P ratio ( $w: \mathrm{w}, \mathrm{N}=\mathrm{NO}_{3}+\mathrm{NH}_{4}$ ) in the surface layer, and stimulation of nitrate and ammonium depletion rate due to phosphate addition $\left(20 \mu \mathrm{g} \mathrm{PO}_{4}-\mathrm{P}^{-1}\right)$. Stimulation is expressed as \% of corresponding unit without phosphate

malized against phytoplankton parameters, a clear nutrient-specific succession was observed (Fig. 10). Nitrate was depleted most effectively per unit chlorophyll during the bloom peak, and the efficiency decreased steadily towards early summer (Fig. 10A). Ammonium depletion per unit chlorophyll increased remarkably during the study period, and early sum-
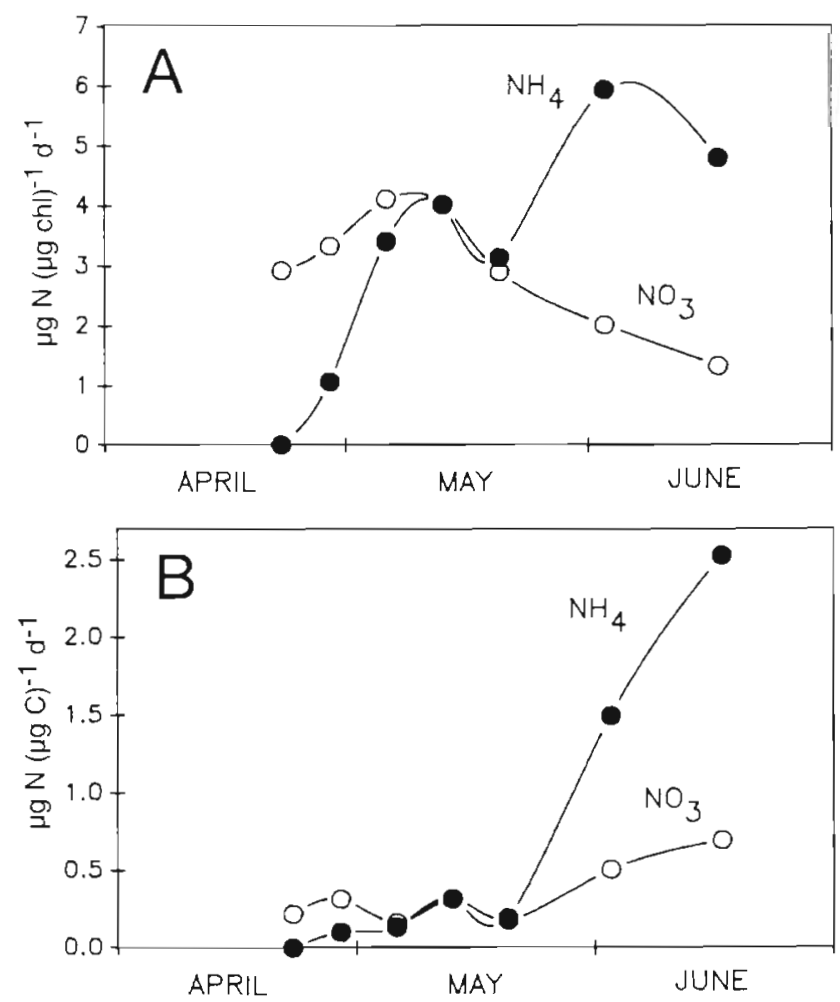

Fig. 10. Nitrate and ammonium depletion rates $\left(100 \mu \mathrm{g} \mathrm{N}^{-1}\right.$ addition units) per (A) chlorophyll $a$ and (B) in situ primary productivity 
mer values were clearly higher than those for either nitrate or ammonium during the bloom peak (Fig. 10A).

When related to primary productivity, the ammonium depletion potential of the early summer community was even more pronounced (Fig 10B). The N:C values do not represent direct assimilation ratios because the primary productivity results originate from non-enriched in situ incubations, but they clearly indicate the qualitative difference between the spring bloom community, dominated by dinoflagellates and diatoms, and the early summer community, dominated by small flagellates.

\section{DISCUSSION}

\section{Stages of nitrogenous nutrition}

Three distinct stages in the nitrogenous nutrition of the community were detected: bloom initiation, bloom peak and postbloom stages all showed specific characteristics of nitrogen utilization.

The bloom started during a period of high nitrate concentrations, and nitrate was highly preferred over ammonium (Fig. 7A) as long as elevated nitrate concentrations prevailed (Figs. 1 \& 5) Nitrate utilization efficiency was accordingly very high (Fig. 7C), indicating dependence on nitrate as the $\mathrm{N}$ source. The community was so clearly adapted to the postwinter nitrate abundance that complete inhibition of ammonium uptake was observed in the first experiment (Figs. 4B \& $7 \mathrm{~A}$ ).

However, ammonium additions already inhibited nitrate uptake during the rising phase of the bloom (Figs. 7D \& 8). This shows that although the community was adapted to nitrate assimilation and still showed a clear preference for nitrate (Fig. 7A), the sudden introduction of energetically more favourable ammonium caused a reorganization of prevailing nitrogen assimilation patterns, and resulted temporarily in lowered total nitrogen uptake (Fig. 8). This occurred with a time lag, as nitrate preference was lower in $24 \mathrm{~h}$ incubations compared to $7 \mathrm{~h}$ incubations (Fig. 7B). The time lag could be seen in $\mathrm{NH}_{4}$ depletion rates as well, as only on 28 April did $24 \mathrm{~h}$ incubation produce higher depletion rates than $7 \mathrm{~h}$ incubation (Fig. 6). This stage resembles the ammonium inhibition of nitrate uptake reported from a permanently high-nitrate environment by Wheeler \& Kokkinakis (1990).

The bloom peak showed equal preference for the 2 nitrogen sources (Fig. 7A, B). Consequently, nitrogen utilization efficiency was not affected by the $\mathrm{N}$ sources present (Fig. 7C). Nitrogen depletion rates were uniformly high (Figs. 5 \& 6), indicating a capacity of the bloom peak community to deplete nitrogen over $24 \mathrm{~h}$ in amounts corresponding to the total winter accumulation of nitrate (ca $100 \mu \mathrm{g} \mathrm{N}{ }^{-1}$ ).

The decreasing bloom was characterized by increasing ammonium preference (Fig. 7 A). In the late bloom situation (19 May), ammonium utilization efficiency clearly exceeded that of nitrate (Fig. 7C), and maximum depletion rate for ammonium was more than double the $V_{\max }$ for nitrate (Fig. 5). Nitrate utilization efficiency decreased steadily towards early summer (Fig, 7C), when the presence of ammonium completely inhibited nitrate uptake (Fig. 7D).

Phosphate addition did not stimulate nitrogen depletion during May (Fig. 9), indicating that the bloom was essentially nitrogen limited. This is supported by extremely low inorganic N:P ratios (Fig. 9), and the observation is in accordance with our experimental results from the area (Kivi et al. 1993).

The emerging phosphate stimulation of $\mathrm{N}$ depletion, as well as the succession of inorganic N:P ratios, indicates colimitation by $\mathrm{N}$ and $\mathrm{P}$ in the early summer stage, which is also in accordance with previous experimental results on nutrient limitation in the area (Kivi et al. 1993).

\section{Preference, inhibition, utilization efficiency, and availability}

In this study, nitrogenous nutrition was studied with enrichments which exceeded ambient nutrient levels. The results therefore illustrate potential qualities of community nutrition. 'Preference' was defined as selection of a given form of $N$ in equal presence of the $N$ sources compared. 'Inhibition' was defined as decrease in utilization of a given form of $\mathrm{N}$ due to presence of the other. 'Utilization efficiency' of a given $N$ source was defined as dependence of total $N$ utilization on availability of the $N$ source in question.

These 3 qualities produced successional results which agreed in their main respects (Fig. 7) - each described an aspect of the shift from nitrate to ammonium as the basis for nitrogenous nutrition of the community. However, they were not identical, and conceptually the differences between the 3 qualities are important. For example, on 28 April nitrate was highly preferred (Fig. 7A), but ammonium inhibited nitrate depletion - not vice versa (Fig. 7D).

It is noteworthy that the abrupt removal of nitrate from the surface layer (Figs. 1 \& 5) was followed by much slower succession in the nutritional characteristics of the community

Dynamic peaks of activity rates (primary productivity, nutrient depletion potential; Figs. 3 \& 5) were recorded immediately after the disappearance of accu- 
mulated nutrients. The phytoplankton biomass (chlorophyll) peak followed in succession (Fig 3). Changes in nitrogen source preferences, inhibition and utilization efficiency (Fig. 7) all showed much more gradual succession, which started at the onset of the bloom, reached a clear culmination point in the relation between nitrate and ammonium during the biomass peak, and continued without abrupt changes throughout the study period. The only exception was the fast disappearance of complete ammonium-uptake inhibition at the bloom initiation (Fig. 7D).

An especially interesting feature was that the gradual nature of this succession differed clearly not only from the dynamic succession of activity rates, but also from the profound changes in species composition of the phytoplankton community during the bloom succession (Heiskanen 1993).

It is obvious that these potential qualities of nitrogenous nutrition (preference, inhibition, utilization efficiency, as well as depletion potential per unit chlorophyll or primary production) were not directly related to in situ nutrient availability, but followed the succession of availability with considerable time lags.

The ecological benefits of 'delayed' succession of nutrition potential are evident: the spring bloom season is characterized by unstable physical conditions, and repeated upwellings commonly occur in the area, providing new inputs - especially of nitrate - and consequently triggering several successive blooms (Niemi \& Åström 1987). In spite of the energetic cost of maintaining the nitrate reductase system, gambling on fresh nitrate inputs is most likely a feasible strategy for spring bloom species. The probability of winning the gamble slowly diminishes with increasing stability of the water column, and the share of gamblers diminishes likewise.

The potential nutritional characteristics of the community thus extend beyond the actual situation of the succession at any particular point, ensuring opportunistic flexibility for the assemblage in responding to sudden environmental changes which affect nutrient availability. The experimental manipulation of nutrient availability produced some eloquent illustrations of this flexibility, which could not be interpreted as direct adaptations to prevailing - or preceding - nutrient conditions.

During the bloom peak, the community was able to utilize both nitrate and ammonium extremely effectively, whichever was made available (Figs. $5 \& 7 \mathrm{C}$ ); during the early summer period, dominated by ammonium according to all the measured characteristics, the community could still utilize nitrate relatively effectively if it was made available (Figs. $7 \mathrm{C} \& 10$ ). Neither of these situations could be explained by the nutrient history of the water column (Figs. 1 \& 2).
Exploring the potential characteristics of nutrient uptake is obviously essential to understanding the competition strategies of different species and assemblages, which shape the actual characteristics of succession. These potential characteristics can be studied only experimentally, by manipulating nutrient availability into alternative directions to prevailing in situ conditions.

\section{New and regenerated production}

The succession of preference during the spring bloom (Fig. 7A) illustrates the general transition of the community from new to regenerated production modes. Dugdale \& Goering (1967) have already stressed the necessity of distinguishing between the relative importance of ammonium and nitrate as nitrogen sources for the phytoplankton cell and for the community as a whole. New and regenerated production are community qualities, which have been widely used to study the dependence of planktonic production on nitrogen sources external or internal to the euphotic zone. The potential features of nitrogenous nutrition presented in this study naturally are community characteristics, but they describe responses at the cellular level.

The preference and mutual inhibition patterns between nitrate and ammonium depletion were observed in treatments with nutrient additions which exceeded concentrations normally encountered during the postbloom period. It is obvious that these patterns relate to cellular nutrient assimilation mechanisms, but only exceptionally to natural situations during the succession.

Despite the dominance of ammonium in preference and inhibition measures during the early summer period when regenerated production prevailed, nitrate depletion potential per unit primary production was higher than during the bloom peak (Fig, 10A). This suggests that even during regenerated-production periods the community has the capacity to respond effectively to sudden nitrate supply. The basic conclusion is thus that, with the exception of bloom initiation, when nitrate concentrations were still at winter levels in the water column, both ammonium and nitrate could be effectively utilized as the nitrogen source for phytoplankton.

Consequently, the relative proportions of new and regenerated production should depend mainly on the relative availability of nitrate and reduced $N$ (ammonium, dissolved organic N), with the exception of blooms of nitrogen-fixing algae. The inherent preferences of the phytoplankton community play a subordinate role, because of the community's flexible nutrient utilization capacity. 
The availability of different nitrogenous nutrients is regulated by processes of very different temporal and spatial scales; for nitrate, mainly by physical transport processes, and for reduced $N$, mainly by community metabolism. It is therefore hardly to be expected that during $\mathrm{N}$ limitation, momentary ambient concentrations could reflect the relative availability of these nutrients, as the application of the Relative Preference Index (McCarthy et al. 1977) presumes.

If preference for alternative $\mathrm{N}$ sources is to be studied, experimental manipulation of nutrient availability is obviously necessary. In the study of causalities behind new and regenerated production, preference experiments should be connected to investigation of nutrient availability, that is, to studies of physical transport in the water column and mineralization processes within the planktonic food web.

Acknowledgements. The study is a contribution to the project PELAG, Tvärminne Zoological Station, University of Helsinki. The study was a part of a joint spring bloom dynamics study by the project PELAG, and I greatly appreciate the generous help from several project members, as well as all the curious, amused and suspicious visitors to the Balcony Laboratory. Torsten Sjölund and Svante Degerholm were indispensable at sea. Elina Salminen was indispensable in the laboratory. Risto Lignell painstakingly assisted in irradiance studies. Anna-Stiina Heiskanen coordinated the whole exercise, first class.

\section{LITERATURE CITED}

Andersen, T., Schartau, A. K. L., Paasche, E. (1991). Quantifying external and internal nitrogen and phosphorus pools, as well as nitrogen and phosphorus supplied through remineralization, in coastal marine plankton by means of a dilution technique. Mar. Ecol. Prog Ser. 69: 67-80

Conway, H. L. (1977). Interactions of inorganic nitrogen in the uptake and assimilation by marine phytoplankton. Mar. Biol. 39: 221-232

Dugdale, R. C., Goering, J. J. (1967). Uptake of new and regenerated forms of nitrogen in primary productivity. Limnol. Oceanogr. 12: 196-206

Eppley, R. W. (1981). Autotrophic production of particulate matter. In: Longhurst, A. R. (ed.) Analysis of marine ecosystems. Academic Press, London, p. 343-361

Eppley, R. W., Carlucci, A. F., Holm-Hansen, O., Kiefer, D., McCarthy, J. J., Venrick, E., Williams, P. M. (1971). Phytoplankton growth and composition in shipboard cultures supplied with nitrate, ammonium or urea as the nitrogen source. Limnol. Oceanogr 16: 741-751

Eppley, R. W., Renger, E. H., Venrick, E. L., Mullin, M. M. (1973). A study of plankton dynamics and nutrient cycling in the central gyre of the North Pacific Ocean. Limnol. Oceanogr. 18: 534-551

Eppley, R. W., Sharp, J. H., Renger, E. H., Perry, M. J., Harrison. W. G. (1977). Nitrogen assimilation by phytoplankton and other microorganisms in the surface waters of the Central North Pacific Ocean. Mar. Biol. 39: 111-120

Furnas, M. J., Smayda, T J., Deason, E. A. (1986). Nitrogen dynamics in lower Narragansett Bay. II. Phytoplankton uptake, depletion rates of nitrogenous nutrient pools, and estimates of ecosystem remineralization. J. Plankton Res. 8: $755-769$

Goldman, J. C. (1984). Oceanic nutrient cycles. In: Fasham, M. J. R. (ed.) Flows of energy and materials in marine ecosystems. Theory and practice. Plenum Press, New York, p. $137-170$

Harvey, W. A., Caperon. J. (1976). The rate of utilization of urea, ammonium, and nitrate by natural populations of marine phytoplankton in a eutrophic environment. Pacif. Sci. 30: 329-340

Heiskanen, A.-S. (1993). Mass encystment and sinking of dinoflagellates during a spring bloom. Mar. Biol. 116 $161-168$

Johnson, K. S., Petty, R. L. (1983). Determination of nitrate and nitrite in sea water by flow-injection analysis. Limnol. Oceanogr. 28: 1260-1266

Kanda, J., Salno, T., Hattori, A. (1985). Nitrogen uptake by natural populations of phytoplankton and primary production in the Pacific Ocean: regional variability of uptake capacity. Limnol. Oceanogr. 30: 987-999

Kivi, K., Kaitala, S., Kuosa, H., Kuparinen, J, Leskinen, E. Lignell, R., Marcussen, B., Tamminen, T. (1993). Nutrient limitation and grazing control of the Baltic plankton community during annual succession. Limnol. Oceanogr. 38: $893-905$

Koroleff, F. (1976). Determination of nutrients. In: Grasshoff, K. (ed.) Methods of seawater analysis. Verlag Chemie, Weinheim, p. 117-133

Kristiansen, S. (1983). Urea as a nitrogen source for the phytoplankton in the Oslofjord. Mar. Biol. 74: 17-24

Lignell, R., Heiskanen, A.-S., Kuosa, H., Gundersen, K., Kuuppo-Leinikki, P., Pajuniemi, R., Uitto, A. (1993). Fate of a phytoplankton spring bloom: sedimentation and carbon flow in the planktonic food web in the northern Baltic. Mar. Ecol. Prog. Ser. 94: 239-252

McCarthy, J. J. (1972). The uptake of urea by natural populations of marine phytoplankton. Limnol. Oceanogr. 17: $738-748$

McCarthy, J. J., Eppley, R. W. (1972). A comparison of chemical, isotopic, and enzymatic methods for measuring nitrogen assimilation of marine phytoplankton. Limnol. Oceanogr. 17: 371-382

McCarthy, J. J., Rowland Taylor, W., Taft, J. L. (1977). Nitrogenous nutrition of the plankton in the Chesapeake Bay. 1. Nutrient availability and phytoplankton preferences. Limnol. Oceanogr. 22: 996-1011

McCarthy, J. J., Wynne, D., Berman, T (1982). The uptake of dissolved nitrogenous nutrients by Lake Kinneret (Israel) microplankton. Limnol. Oceanogr. 27: 673-680

Mitamura, O., Saijo, Y. (1986). Urea metabolism and its significance in the nitrogen cycle in the euphotic layer of Lake Biwa. I. In situ measurement of nitrogen assimilation and urea decomposition. Arch. Hydrobiol. 107: 23-51

Molloy, C. J., Syrett, P. J. (1988a). Interrelations between uptake of urea and uptake of ammonium by microalgae. J. exp. mar. Biol. Ecol 118: 85-95

Molloy, C. J., Syrett, P. J. (1988b). Effect of light and N deprivation on inhibition of nitrate uptake by urea in microalgae. J. exp. mar. Biol. Ecol. 118: 97-101

Niemi, Å., Åstrom, A.-M. (1987). Ecology of phytoplankton in the Tvärminne area, SW coast of Finland. IV. Environmental conditions, chlorophyll $a$ and phytoplankton in winter and spring 1984 at Tvärminne Storfjard. Annls bot. fenn. 24: 333-352

Paasche, E., Kristiansen, S. (1982a). Nitrogen nutrition of the phytoplankton in the Oslofjord. Estuar. coast. Shelf Sci. 14: $237-249$ 
Paasche, E., Kristiansen, S. (1982b). Ammonium regeneration by microzooplankton in the Oslofjord. Mar. Biol. 69: $55-63$

Ryther, J. H., Dunstan, W. M. (1971). Nitrogen, phosphorus, and eutrophication in the coastal marine environment. Science 171: 1008-1013

Sahlsten, E., Sörensson, F., Pettersson, K. (1988). Planktonic nitrogen uptake in the south-eastern Kattegat. J. exp. mar Biol. Ecol. 121: 227-246

Sörensson, F., Pettersson, K., Selmer, J.-S., Sahlsten, E. (1989).

This article was submitted to the editor
Flows of nitrogen in a mesocosm experiment in the Baltic Sea. Mar. Ecol. Prog. Ser. 58: 77-88

Sverdrup, H. U. (1952). On conditions for the vernal blooming of phytoplankton. J. Cons. int. Explor. Mer 18: 287-295

Wheeler, P. A., Kokkinakıs, S. A. (1990). Ammonium recycling limits nitrate use in the oceanic subarctic Pacific Limnol. Oceanogr. 35: 1267-1278

Wright, R. T., Hobbie, J. E. (1966). Use of glucose and acetate by bacteria and algae in aquatic ecosystems. Ecology 47 $447-464$

Manuscript first received: September 12, 1989 Revised version accepted: December 27, 1994 